\begin{tabular}{c} 
TẠP CHÍ KHOA HỌC ĐẠI HỌC TÂN TRÀO \\
ISSN: 2354 - 1431 \\
\hline
\end{tabular}

\title{
Nâng cao hiệu quả quản lý hành chính nhà nước tại tỉnh Tuyên Quang hiện nay
}

\author{
Hà Thị Thu Trang ${ }^{a^{*}}$ \\ ${ }^{a}$ Trưòng Đại học Tân Trào \\ *Email: hathutrang.ht@gmail.com
}

\section{Thông tin bài viết}

Ngày nhận bài:

02/12/2019

Ngày duyệt đăng:

$10 / 3 / 2020$

Tì khóa:

Quản lý hành chính nhà nuớc; cải cách hành chính; phát triển kinh tế - xã hội.

\section{Tóm tắt}

Quản lý hành chính nhà nước là một hoạt động công vụ quan trọng của hệ thống chính trị, các nội dung của hoạt động quản lý hành chính nhà nước được thực hiện sao cho phù hợp với hoàn cảnh thực tiễn của từng địa phương, góp phần thúc đẩy phát triển kinh tế - xã hội, nâng cao đời sống nhân dân. Thông qua việc nhìn nhận, đánh giá hoạt động quản lý hành chính nhà nước tại Tuyên Quang để đề xuất những giải pháp nhằm nâng cao hiệu quả quản lý hành chính của địa phương là một yêu cầu bức thiết hiện nay.

\section{1. Đặt vấn đề}

Quản lý hành chính Nhà nước là hoạt động chấp hành, điều hành của cơ quan hành chính Nhà nước, của các cơ quan Nhà nước khác và các tổ chức được Nhà nước ủy quyền quản lý trên cơ sở của luật và để thi hành luật nhằm thực hiện chức năng tổ chức, quản lý, điều hành các quá trình xã hội của Nhà nước.

Hoạt động quản lý nhà nước của các cơ quan quản lý hành chính nhà nước tỉnh Tuyên Quang trong những năm qua đã đạt được những thành tựu nhất định, góp phần phát triển kinh tế - xã hội của địa phương.

Nghị quyết Đại hội đại biểu Đảng bộ tỉnh Tuyên Quang lần thứ XVI, nhiệm kỳ 2015-2020 đã xác định mục tiêu tổng quát của nhiệm kỳ: "Nâng cao năng lực lãnh đạo và sức chiến đấu của Đảng bộ, phát huy dân chủ và sức mạnh đoàn kết dân tộc, tiếp tục đổi mới mạnh mẽ và vững chắc, phát triển kinh tế nhanh và bền vững, cơ cấu hợp lý; nâng cao đời sống vật chất và tinh thần của nhân dân; bảo đảm quốc phòng, an ninh, giữ vững ổn định chính trị, trật tự an toàn xã hội, phấn đấu đưa Tuyên Quang trở thành tỉnh phát triển khá trong các tỉnh miền núi phía Bắc." (Nghi quyết
Đại hội đại biểu Đảng bộ tỉnh Tuyên Quang lần thư XVI, nhiệm kỳ 2015-2020)

Các cơ quan quản lý hành chính nhà nước tỉnh Tuyên Quang hiện nay không ngừng hoàn thiện về cơ cấu tổ chức và hoạt động chuyên môn để thực hiện thắng lợi mục tiêu của Nghị quyết đã đề ra. Nâng cao hiệu quả quản lý hành chính nhà nước được xác định là một giải pháp quan trọng để phát huy vai trò của cơ quan quản lý hành chính nhà nước tỉnh Tuyên Quang hiện nay.

2. Những vấn đề chung về hoạt động quản lý hành chính nhà nước tại tỉnh Tuyên Quang

\subsection{Hệ thống co quan quản lý hành chính nhà} nước tỉnh Tuyên Quang

Hệ thống cơ quan quản lý hành chính nhà nước tỉnh Tuyên Quang hiện nay được phân chia theo ba (03) cấp: cấp tỉnh, cấp huyện và cấp xã. Cụ thể:

* Cấp tỉnh: Gồm 20 cơ quan chuyên môn, tổ chức hành chính (không bao gồm Văn phòng Hội đồng nhân dân tỉnh và Văn phòng Đoàn đại biểu Quốc hội), trong đó có 19 cơ quan chuyên môn và 01 tổ chức hành chính (Ban Quản lý các khu công nghiệp tỉnh); có 145 đầu mối (chi cục, ban, phòng và tương đương). 
* Cấp huyện: Gồm 06 huyện và 01 thành phố. Số lượng cơ quan chuyên môn thuộc Ủy ban nhân dân cấp huyện: 84 phòng chuyên môn, trong đó: Ủy ban nhân dân huyện Yên Sơn có 10 phòng; Ủy ban nhân dân huyện Lâm Bình có 12 phòng; Ủy ban nhân dân huyện Sơn Dương có 11 phòng; Ủy ban nhân dân các huyện: Na Hang, Chiêm Hóa, Hàm Yên có 13 phòng; Ủy ban nhân dân thành phố có 12 phòng.

* Cấp xã: Toàn tỉnh hiện nay có 141 xã, phường, thị trấn ( 07 phường, 05 thị trấn, 129 xã) 1.739 thôn, tổ dân phố.

Các cơ quan hành chính gồm cơ quan chuyên môn, cơ quan hành chính và ủy ban nhân dân các cấp thực hiện theo đúng chức năng, nhiệm vụ của từng đơn vị;; có trách nhiệm phối hợp, liên kết với các đơn vị khác trong việc thực hiện nhiệm vụ chuyên môn, từ đó hoàn thành nhiệm vụ chung về ổn định chính trị, phát triển kinh tế - xã hội, đảm bảo an ninh - quốc phòng, nâng cao đời sống nhân dân của địa phương.

\subsection{Thục trạng hoạt động quản lý hành chính} nhà nước tại Tuyên Quang hiện nay

Hoạt động quản lý hành chính nhà nước tại tỉnh Tuyên Quang thời gian qua đã và đang thể chế hóa các chủ trương của Đảng trong các nghị quyết như: Nghị quyết số $18-\mathrm{NQ} / \mathrm{TW}$ ngày $25 / 10 / 2017$, Hội nghị lần thứ sáu ban chấp hành trung ương khoá XII "Một số vấn đề về tiếp tục đổi móit, sắp xếp tổ chức bộ máy của hệ thống chinh trị tinh gọn, hoạt động hiệu lưc, hiệu quả" và Nghị quyết số 19-NQ/TW ngày 25/10/2017, Hội nghị lần thứ sáu ban chấp hành trung ương khoá XII "Về tiếp tục đổi mới hệ thống tổ chức và quản lý, nâng cao chất luợng và hiệu quả hoạt động của các đơn vị sư nghiệp công lập". Vì vậy, hoạt động quản lý hành chính nhà nước trên địa bàn tỉnh Tuyên Quang đã đạt được một số kết quả như sau:

\subsubsection{Một số mặt tích cưc}

a) Về xây dựng và thực hiện thể chế hành chính nhà nước

- Hội đồng nhân dân tỉnh, Ủy ban nhân dân tỉnh đã ban hành các văn bản quy phạm pháp luật: Ủy ban nhân dân tỉnh đã ban 22 quyết định quy định tiêu chuẩn, điều kiện bổ nhiệm Trưởng phòng, Phó Trưởng phòng và tương đương của các cơ quan, đơn vị cho phù hợp với yêu cầu nhiệm vụ.

- Công tác theo dõi thi hành pháp luật, công tác kiểm tra, rà soát văn bản quy phạm pháp luật được thực hiện hằng năm theo kế hoạch bảo đảm đúng quy định. Rà soát, xử lý các văn bản không còn phù hợp với Hiến pháp, pháp luật và tình hình kinh tế - xã hội của địa phương.

- Công tác theo dõi tình hình thi hành pháp luật tập trung vào lĩnh vực trọng tâm như: Lĩnh vực hỗ trợ doanh nghiệp khởi nghiệp, về đăng ký thế chấp quyền sử dụng đất, tài sản gắn liền với đất, về điều kiện đầu tư, kinh doanh trong lĩnh vực y tế, lao động thương binh xã hội, tài nguyên và môi trường.

b) Về tổ chức bộ máy

- Thực hiện việc phân cấp, phân quyền cho các cơ quan, đơn vị thuộc và trực thuộc Ủy ban nhân dân tỉnh, Ủy ban nhân dân huyện, thành phố gắn với tăng cường kiểm tra, giám sát và kiểm soát quyền lực, Ủy ban nhân dân tỉnh ban hành Quyết định số 04/2018/QĐ-UBND ngày 10/7/2019 sửa đổi, bổ sung một số điều của Quy định phân cấp quản lý viên chức ban hành kèm theo Quyết định số 33/2013/QĐ-UBND ngày 20/12/2013; Quyết định số 09/2018/QĐ-UBND ngày $05 / 11 / 2018$ sửa đổi, bổ sung một số điều của Quy định phân cấp quản lý cán bộ, công chức ban hành kèm theo Quyết định số 32/2013/QĐ-UBND ngày $20 / 12 / 2013$.

- Đến tháng 6/2019, Ủy ban nhân dân tỉnh đã ban hành 09 quyết định quy định mới hoặc điều chỉnh, bổ sung chức năng, nhiệm vụ, quyền hạn, cơ cấu tổ chức bộ máy thuộc thẩm quyền để khắc phục tình trạng trùng lặp, chồng chéo về chức năng, nhiệm vụ, quyền hạn, mối quan hệ công tác giữa các cơ quan, đơn vị, tổ chức để nâng cao hiệu lực, hiệu quả hoạt động theo tinh thần Nghị quyết số $18-\mathrm{NQ} / \mathrm{TW}$ Hội nghị lần thứ sáu Ban Chấp hành Trung ương Đảng khóa XII.

- Thực hiện Nghị quyết số 19-NQ/TW ngày 25/10/2017 Hội nghị lần thứ sáu Ban Chấp hành Trung ương Đảng khóa XII, Ban cán sự Đảng Ủy ban nhân dân tỉnh đã tập trung lãnh đạo, chỉ đạo thực hiện sắp xếp các đơn vị sự nghiệp công lập, đến tháng 9/2019, tỉnh có 598 đơn vị sự nghiệp công lập, giảm 16 đơn vị sự nghiệp; giảm 66 đầu mối phòng và tương đương; giảm 103 lãnh đạo (23 truởng đơn vị sụ nghiệp công lập, 17 phó truởng đơn vị sư nghiệp công lậ, 35 trưởng phòng, 35 phó truởng phòng và tuoong duong).

c) Sắp xếp các cơ quan, tổ chức hành chính

- Cấp tỉnh: Giảm 05 phòng và tương đương $(02$ phòng chuyên môn, nghiệp vu thuộc Sở Y tế, 02 phòng chuyên môn, nghiệp vu thuộc Ban Quản lý các khu công nghiệp, 01 Chi cuc Quản lý thị truờng trục thuộc Sở Công Thuoong); giảm 17 đơn vị sự nghiệp trực 
thuộc các cơ quan chuyên môn (16 đơn vị thuộc $S o ̛ ̉ ~ Y$ tế, 01 đơn vị thuộc Sở Tài nguyên và Môi truò̀ng); giảm 62 đầu mối bên trong các cơ quan, đơn vị trực thuộc sở, gồm: Sở Y tế 37 đầu mối (25 phòng và tuoong đưong, 09 Trạm $Y$ tế xã 03 phòng khám đa khoa khu vục) và 11 phòng, bộ môn thuộc Trường Trung cấp Y tế; Sở Tài nguyên và Môi trường (giảm 11 đầu mối: 05 phòng, 06 chi nhánh thuộc Trung tâm phát triển quỹ đất); Ban Quản lý các khu công nghiệp tỉnh (03 phòng thuộc Công ty phát triển hạ tầng khu công nghiệp).

- Cấp huyện: Có 07 huyện, thành phố với 84 phòng chuyên môn (giảm 06 phòng chuyên môn), trong đó: Ủy ban nhân dân huyện Yên Sơn có 10 phòng (giảm 03 phòng do hơp nhất với co quan khối đảng); Ủy ban nhân dân huyện Lâm Bình có 12 phòng (giảm 01 phòng do hơp nhất co quan khối đảng); Ủy ban nhân dân huyện Sơn Dương có 11 phòng (giảm 02 phòng do hợp nhất với co quan khối đảng); Ủy ban nhân dân các huyện: Na Hang, Chiêm Hóa, Hàm Yên có 13 phòng; Ủy ban nhân dân thành phố có 12 phòng.

d) Xây dựng và nâng cao chất lượng đội ngũ cán bộ, công chức, viên chức

- Thực hiện các quy định về quản lý cán bộ, công chức, viên chức theo đúng quy định tại Luật cán bộ, công chức và Luật Viên chức:

+ Hoàn thiện quy định của pháp luật về tuyển dụng, bố trí, phân công nhiệm vụ phù hợp với trình độ, năng lực, sở trường của công chức, viên chức trúng tuyển; thực hiện chế độ thi nâng ngạch theo nguyên tắc cạnh tranh;

+ Hoàn thiện quy định của pháp luật về đánh giá cán bộ, công chức, viên chức trên cơ sở kết quả thực hiện nhiệm vụ được giao; thực hiện cơ chế loại bỏ, bãi miễn những người không hoàn thành nhiệm vụ, vi phạm kỷ luật, mất uy tín với nhân dân; quy định rõ nhiệm vụ,quyền hạn của cán bộ, công chức, viên chức tương ứng với trách nhiệm và có chế tài nghiêm đối với hành vi vi phạm pháp luật, vi phạm kỷ luật, vi phạm đạo đức công vụ của cán bộ, công chức, viên chức;

- Thực hiện tốt công tác đào tạo, bồi dưỡng cán bộ, công chức:

+ Đổi mới nội dung và chương trình đào tạo, bồi dưỡng cán bộ, công chức, viên chức; thực hiện việc đào tạo, bồi dưỡng theo các hình thức: Hướng dẫn tập sự trong thời gian tập sự; bồi dưỡng theo tiêu chuẩn ngạch công chức, viên chức; đào tạo, bồi dưỡng theo tiêu chuẩn chức vụ lãnh đạo, quản lý; bồi dưỡng bắt buộc kiến thức, kỹ năng tối thiểu trước khi bổ nhiệm và bồi dưỡng hàng năm;

+ Đã xây dựng được đội ngũ cán bộ, công chức, viên chức có phẩm chất đạo đức tốt, có bản lĩnh chính trị, có năng lực, có tính chuyên nghiệp cao, tận tụy phục vụ nhân dân thông qua các hình thức đào tạo, bồi dưỡng phù hợp, có hiệu quả.

e) Cải cách tài chính công

Ủy ban nhân dân tỉnh đã chỉ đạo các cơ quan, đơn vị thực hiện khoán kinh phí theo đúng quy định tại Nghị định số 130/2005/NĐ-CP ngày 17/10/2005 của Chính phủ, Nghị định số 117/2013/NĐ-CP về sửa đổi, bổ sung một số điều của Nghị định 130/2005/NĐ-CP, Nghị định số 16/2015/NĐ-CP ngày 14/02/2015 của Chính phủ Quy định cơ chế tự chủ của đơn vị sự nghiệp công lập; phân cấp ngân sách toàn diện cho các huyện, thành phố theo Luật Ngân sách nhà nước.

g) Hiện đại hoá hành chính

- Đẩy mạnh ứng dụng công nghệ thông tin theo kế hoạch ứng dụng Công nghệ thông tin trong hoạt động cơ quan nhà nước tỉnh Tuyên Quang giai đoạn 2016 2020 và hằng năm. Thực hiện cung cấp dịch vụ công trực tuyến mức độ 3,4 .

- Tiếp tục áp dụng, duy trì, cải tiến hệ thống quản lý chất lượng theo tiêu chuẩn ISO vào hoạt động cơ quan và công bố Hệ thống quản lý chất lượng tiêu chuẩn Quốc gia 9001 vào hoạt động của các cơ quan, tổ chức thuộc hệ thống hành chính nhà nước.

\subsubsection{Một số mặt hạn chế}

a) Về xây dựng và thực hiện thể chế hành chính nhà nước

Thủ tục hành chính tuy đã được cải cách nhưng vẫn còn nhiều bất cập, chưa triệt để dẫn đến tình trạng “một cửa nhưng nhiều bàn". Có nhiều quyết định hành chính còn mang tính chủ quan của người ban hành dẫn đến vừa không hợp pháp lại vừa không hợp lý.

b) Về tổ chức bộ máy

- Tổ chức bộ máy của hệ thống chính trị vẫn còn cồng kềnh, nhiều tầng nấc, nhiều đầu mối; hiệu lực, hiệu quả hoạt động chưa đáp ứng yêu cầu, nhiệm vụ. Chức năng, nhiệm vụ, quyền hạn, tổ chức bộ máy, mối quan hệ của một số cơ quan, tổ chức chưa thật rõ, còn chồng chéo, trùng lắp

- Việc phân công, phân cấp, phân quyền giữa các ngành, các cấp và trong từng cơ quan, tổ chức 
chưa hợp lý, mạnh mẽ và đồng bộ; còn tình trạng bao biện, làm thay hoặc bỏ sót nhiệm vụ.

- Sự phối hợp giữa các cấp, các ngành, các địa phương có lúc, có nơi thiếu chặt chẽ. Các đơn vị hành chính địa phương nhìn chung quy mô nhỏ, nhiều đơn vị không bảo đảm tiêu chuẩn theo quy định, nhất là cấp huyện, cấp xã. Số lượng, cơ cấu đại biểu dân cử chưa phù hợp, chất lượng còn hạn chế...

c) Về xây dựng và phát triển đội ngũ $\mathrm{CBCC}$

Một số cán bộ, công chức còn hạn chế về trình độ cũng như phẩm chất đạo đức. Tình trạng tham nhũng vẫn còn tồn tại và có nhiều diễn biến phức tạp. Một số cán bộ, công chức trong bộ máy hành chính nhà nước còn mắc bệnh quan liêu, xa dân, xa cấp dưới và cấp cơ sở.

d) Về quản lý tài chính công

Hoạt động quản lý tài chính công đã được thực hiện dựa trên các văn bản quy phạm pháp luật. Tuy nhiên, ở một số cơ sở, đơn vị nhỏ vẫn còn tình trạng kém minh bạch, rõ ràng trong công khai, sử dụng và quả lý tài chính công.

e) Về hiện đại hóa nền hành chính

Đa số các hoạt động quản lý hành chính trên địa bàn hiện nay được ứng dụng công nghệ thông tin; áp dụng, duy trì, cải tiến hệ thống quản lý chất lượng theo tiêu chuẩn ISO vào hoạt động cơ quan; tuy nhiên vì những lý do khách quan và chủ quan mà một số cơ quan, đơn vị chưa cập nhật và ứng dụng công nghệ thông tin một cách hiệu quả trong quản lý.

\section{Một số giải pháp nâng cao hiệu lực, hiệu quả quản lý nhà nước}

Trong thời gian qua, hoạt động quản lý nhà nước tại tỉnh Tuyên Quang đã đạt được nhiều kết quả tích cực, đáng khích lệ, nhận được sự tin tưởng, hài lòng của người dân và tổ chức, song vẫn còn tồn tại một số hạn chế nhất định. Do đó, để nâng cao hiệu lực, hiệu quả quản lý nhà nước tại địa phương hiện nay cần thực hiện đồng bộ các giải pháp sau:

3.1. Tiếp tục đổi mói, sắp xếp tổ chức bộ máy của hệ thống chính trị tinh gọn, hoạt động hiệu lục, hiệu quả

- Xây dựng Đề án về số lượng cơ quan chuyên môn cấp tỉnh, số lượng lãnh đạo cấp phó, số lượng phòng, ban, đơn vị trực thuộc của cơ quan chuyên môn thuộc Ủy ban nhân dân tỉnh sau khi có Nghị định của Chính phủ.

- Chỉ đạo Ủy ban nhân dân huyện, thành phố xây dựng Đề án về số lượng cơ quan chuyên môn, số lượng lãnh đạo cấp phó trong các cơ quan chuyên môn thuộc Ủy ban nhân dân cấp huyện sau khi có Nghị định của Chính phủ.

- Rà soát, bổ sung, hoàn thiện Đề án chức năng, nhiệm vụ, quyền hạn, cơ cấu tổ chức bộ máy của các cơ quan, đơn vị, tổ chức theo quy định của Trung ương để khắc phục tình trạng trùng lặp, chồng chéo về chức năng, nhiệm vụ, quyền hạn, mối quan hệ công tác giữa các cơ quan, đơn vị, tổ chức trong hệ thống và nâng cao hiệu lực, hiệu quả hoạt động.

- Thực hiện Đề án điều chỉnh địa giới hành chính để mở rộng thành phố và thành lập phường thuộc thành phố Tuyên Quang, Đề án sắp xếp đơn vị hành chính cấp xã thuộc tỉnh Tuyên Quang giai đoạn 20202025.

- Quyết định số lượng người làm việc tối thiểu, cắt giảm phù hợp số lượng người làm việc và xây dựng giải pháp giải quyết dứt điểm số viên chức và số người lao động vượt quá số biên chế được giao.

3.2. Đổi mới hệ thống tổ chức và quản lý, nâng cao chất luọng và hiệu quả hoạt động của các đơn vị sụr nghiệp công lập

- Xây dựng và thực hiện các Đề án sắp xếp, tổ chức lại các đơn vị sự nghiệp công lập.

- Hoàn thiện Đề án vị trí việc làm trong các đơn vị sự nghiệp công lập sau khi sáp nhập, hợp nhất và thực hiện quản lý, sử dụng viên chức theo vị trí việc làm.

- Thực hiện việc quản lý số lượng người làm việc đối với các tổ chức hội được giao số lượng người làm việc; từng bước thực hiện khoán hoặc hỗ trợ kinh phí để thực hiện nhiệm vụ Đảng, Nhà nước giao.

- Đổi mới phương thức quản lý, nâng cao năng lực quản trị đơn vị sự nghiệp công lập. Nâng cao trách nhiệm của người đứng đầu đơn vị sự nghiệp công lập trong việc quản trị tài chính, tài sản công của đơn vị.

- Đẩy mạnh việc phân cấp, giao quyền tự chủ cho các đơn vị sự nghiệp công lập theo hướng phân định rõ việc quản lý nhà nước với quản trị đơn vị sự nghiệp công lập và việc cung ứng dịch vụ sự nghiệp công.

- Hoàn thiện quy hoạch mạng lưới các đơn vị sự nghiệp công lập đối với các đơn vị chưa được phê duyệt; tiếp tục rà soát, điều chỉnh bổ sung quy hoạch mạng lưới các đơn vị sự nghiệp công lập đối với các đơn vị đã được phê duyệt.

\section{3. Đẩy mạnh thục hiện công tác cải cách hành} chính và phát huy kết quả đạt được

- Tiếp tục đẩy mạnh cải cách hành chính với mục tiêu xây dựng nền hành chính phục vụ, mang đến sự 
hài lòng cho người dân và doanh nghiệp. Các cơ quan, đơn vị, địa phương phải đẩy mạnh cải cách thủ tục hành chính trên tất cả các lĩnh vực, loại bỏ những thủ tục hành chính gây phiền hà cho người dân và doanh nghiệp; tạo bước thay đổi mạnh mẽ môi trường hành chính công khai, minh bạch.

- Xây dựng nền hành chính hiệu lực, hiệu quả, kỷ luật, kỷ cương; chính quyền thân thiện hơn, thủ tục hành chính đơn giản hơn, thời gian giải quyết thủ tục hành chính nhanh hơn, phương thức phục vụ hiện đại hơn và người dân hài lòng hơn.

- Cần khắc phục tình trạng chậm trễ, đùn đẩy, né tránh trong việc giải quyết các yêu cầu của doanh nghiệp và người dân; lấy sự hài lòng của người dân và doanh nghiệp làm thước đo hiệu quả hoạt động của chính quyền các cấp; giảm bớt tiêu cực, nhũng nhiễu trong quá trình giải quyết công việc cho tổ chức, cá nhân; tăng cường kỷ luật, kỷ cương hành chính, nâng cao đạo đức công vụ, tạo ra sự chuyển biến mạnh mẽ, đồng bộ ở các cấp, ngành trong toàn tỉnh.

- Từ cải cách hành chính tốt, chúng ta sẽ cải thiện được môi trường đầu tư, nâng cao cạnh tranh, thu hút đầu tư huy động và sử dụng có hiệu quả mọi nguồn lực để thúc đẩy phát triển kinh tế xã hội của tỉnh.

- Để nâng cao hiệu lực, hiệu quả của quản lý hành chính nhà nước thì công việc quan trọng là cải cách nền hành chính. Cải cách hành chính ở Việt Nam là công việc mới mẻ, diễn ra trong điều kiện thiếu kiến thức và kinh nghiệm, có nhiều vấn đề vừa phải làm, vừa tìm tòi rút kinh nghiệm.

- Vì vậy, việc hình thành quan niệm và những nguyên tắc cơ bản chỉ đạo công cuộc cải cách hành chính cũng như việc đề ra những nội dung, phương hướng, chủ trương, giải pháp thực hiện trong từng giai đoạn là một quá trình tìm tòi sáng tạo không ngừng, là một quá trình nhận thức liên tục, thống nhất. Trên cơ sở những nghiên cứu và rút kinh nghiệm vấn đề quản lý hành chính nhà nước ở Việt Nam sẽ ngày càng tinh gọn, tránh phiền hà mà vẫn đảm bảo được yêu cầu quản lý.

\section{Kết luận}

Quản lý hành chính nhà nước là một hoạt động hết sức quan trọng của cả nước nói chung và của tỉnh Tuyên Quang nói riêng. Để pháp luật có thể đi vào thực tế và phát huy hiệu lực cần phải có hoạt động quản lý hành chính nhà nước. Vấn đề quản lý hành chính nhà nước là vấn đề được cả xã hội quan tâm, bởi xã hội ngày càng phát triển phức tạp dẫn đến yêu cầu quản lý ngày càng cao, đặc biệt là hoạt động quản lý hành chính nhà nước là hoạt động thường xuyên thay đổi. Chính vì vậy vấn đề nâng cao hiệu lực, hiệu quả của quản lý hành chính nhà nước luôn được quan tâm sâu sắc ở từng cấp, ngành, từng cơ quan đơn vị trong toàn tỉnh. Toàn thể cán bộ, công chức viên chức trong bộ máy hành chính nhà nước tỉnh Tuyên Quang sẽ cố gắng nỗ lực hoàn thành tốt nhiệm vụ để phát huy tối đa hiệu quả, hiệu lực quản lý hành chính nhà nước trong thời gian tới./.

\section{TÀI LIỆU THAM KHẢO}

1. Đảng bộ tỉnh Tuyên Quang, Nghị quyết Đại hội đại biểu Đảng bộ tỉnh Tuyên Quang lần thứ XVI, nhiệm kỳ 2015-2020.

2. Đảng Cộng sản Việt Nam (2017), Nghị quyết số 18-NQ/TW, Hội nghị lần thứ sáu Ban chấp hành Trung ương Đảng khoá XII.

3. Đảng Cộng sản Việt Nam (2017), Nghị quyết số 19-NQ/TW ngày 25/10/2017, Hội nghị lần thứ sáu Ban chấp hành Trung ương Đảng khoá XII.

4. Quốc hội nước Cộng hòa xã hội chủ nghĩa Việt Nam (2010), Luật Viên chức, NXB Tư pháp.

5. Quốc hội nước Cộng hòa xã hội chủ nghĩa Việt Nam (2008), Luật Cán bộ, công chức, NXB Tư pháp.

6. Thủ tướng Chính phủ (2005), Nghị định số 130/2005/NĐ-CP ngày 17/10/2005 của Chính phủ.

7. Thủ tướng Chính phủ (2013), Nghị định số 117/2013/NĐ-CP về sửa đổi, bổ sung một số điều của Nghị định 130/2005/NĐ-CP.

8. Thủ tướng Chính phủ (2015), Nghị định số 16/2015/NĐ-CP ngày 14/02/2015 của Chính phủ Quy định cơ chế tự chủ của đơn vị sự nghiệp công lập; phân cấp ngân sách toàn diện cho các huyện, thành phố theo Luật Ngân sách nhà nước.

9. Ủy ban nhân dân tỉnh Tuyên Quang (2018), Quyết định số 04/2018/QĐ-UBND ngày 10/7/2019 sửa đổi, bổ sung một số điều của Quy định phân cấp quản lý viên chức ban hành kèm theo Quyết định số 33/2013/QĐ-UBND ngày 20/12/2013.

10. Ủy ban nhân dân tỉnh Tuyên Quang (2018), Quyết định số 09/2018/QĐ-UBND ngày 05/11/2018 sửa đổi, bổ sung một số điều của Quy định phân cấp quản lý cán bộ, công chức ban hành kèm theo Quyết định số 32/2013/QĐ-UBND ngày 20/12/2013. 


\section{Improving the efficiency of state administrative management in Tuyen Quang province today}

Ha Thi Thu Trang

\section{Article info}

Recieved:

02/12/2019

Accepted:

10/3/2020

Keywords:

Government

administrative

management;

administrative reform;

social economic

development

\begin{abstract}
State administrative management is an important public activity of the political system, the contents of state administrative management are implemented in accordance with the real situation of each locality, contributing to promote socioeconomic development and improve people's life. We would like to propose solutions to improve the efficiency of local administrative management through the recognition and evaluation of state administrative management activities in Tuyen Quang province which is an urgent requirement now
\end{abstract}

